\title{
Effect of Aging on Low-temperature Tensile Properties of Ultra- Iow Carbon Steel
}

\author{
Norimitsu KOGA, ${ }^{1) *}$ Yuki KANEHIRA, ${ }^{2)}$ Pham Thi Thanh HUYEN,${ }^{2)}$ Kazuya HORI ${ }^{2)}$ and Osamu UMEZAWA ${ }^{3)}$ \\ 1) Faculty of Mechanical Engineering, Institute of Science and Engineering, Kanazawa University, Kakumamachi, Kanazawa, \\ Ishikawa, 920-1192 Japan. \\ 2) Graduate School of Engineering, Yokohama National University, 79-5 Tokiwadai, Hodogaya, Yokohama, $240-8501$ Japan. \\ 3) Faculty of Engineering, Yokohama National University, 79-5 Tokiwadai, Hodogaya, Yokohama, $240-8501$ Japan.
}

(Received on April 7, 2021; accepted on May 24, 2021)

\begin{abstract}
The microstructural changes and low-temperature tensile properties of ultra-low carbon steel aged at $443 \mathrm{~K}$ were examined, and the relationship between the low-temperature tensile properties and ultra-low carbon state was discussed. Fine cementites of approximately $60 \mathrm{~nm}$ were observed at $0.6 \mathrm{ks}$ and coarsened to approximately $800 \mathrm{~nm}$ at $600 \mathrm{ks}$. The yield and tensile stresses at $77 \mathrm{~K}$ increased until $6 \mathrm{ks}$ and then decreased. The nominal stress-strain curves of all the specimens at $77 \mathrm{~K}$ exhibited low elastic limits, the nominal stress plateaued from an approximate nominal strain of 0.002 and, subsequently, work hardening occurred. In the unaged and 6 ks aged specimens, several twins were generated after the elastic limit, and which increased dramatically in the nominal stress plateau regime, and corresponded to macroscopic yielding. In contrast, the number of twins in the $600 \mathrm{ks}$ aged specimen negligibly increased during macroscopic yielding. Macroscopic yielding occurred in the unaged and $6 \mathrm{ks}$ aged specimens by deformation twinning, while in the $600 \mathrm{ks}$ aged specimen it occurred by slip deformation. In the $6 \mathrm{ks}$ aged specimen, the fine cementites and/or decrease in solid solute carbon enhanced the critical resolved shear stresses of deformation twinning, resulting in the highest strength. In the $600 \mathrm{ks}$ aged specimen, the coarse cementites negligibly enhanced the critical resolved shear stress for slip deformation. Hence, the strength of the specimen aged for $600 \mathrm{ks}$ decreased as compared to the specimen aged for $6 \mathrm{ks}$, and slip deformation occurred.
\end{abstract}

KEY WORDS: ultra-low carbon steel; aging; precipitate; low-temperature tensile property; twin.

\section{Introduction}

Carbon is the most important alloying element for strengthening conventional steels and strongly affects their mechanical properties, even in very small amounts such as tens of ppm. Bake hardening steels use carbon to improve their mechanical properties. ${ }^{1-3)}$ In particular, strain aging occurs during the paint-baking procedure of stamped bakehardening steels and improves the hardness. Maruyama et $a l^{4)}$ investigated the segregation of carbon atoms to dislocations and the carbide precipitation behavior during strain aging of ultra-low carbon steels with 43 ppm. They concluded that the amount of carbon atoms segregating to dislocations was approximately $5 \mathrm{ppm}$, and the strength of the steel is mainly enhanced by carbide precipitates. It has also been reported that ultra-low carbon significantly affects the Hall-Petch coefficient of ferritic steel. ${ }^{5)}$ Segregation of carbon atoms to the grain boundary occurs during

\footnotetext{
* Corresponding author: E-mail: koga-norimitsu@se.kanazawa-u.ac.jp
}

low-temperature aging in ultra-low carbon steels, enhancing the grain boundary strength, and hardening the steel through an increase in the Hall-Petch coefficient. ${ }^{6,7)}$ At high temperatures, ultra-low carbon also plays an important role in improving the mechanical properties. Using a small ball rebound hardness test, ${ }^{8)}$ Koga et al. ${ }^{9)}$ demonstrated that a solid solution of ultra-low carbon (approximately $100 \mathrm{ppm}$ ) in the matrix significantly enhanced the high-temperature hardness of steels with various carbon concentrations. The effect of ultra-low carbon on the mechanical properties of steels above room temperature has been widely investigated; however, it is still unclear whether ultra-low carbon influences the mechanical properties at low temperatures.

Ultra-low carbon steels consist of a ferrite (bcc) single phase and exhibit strong temperature-dependent mechanical properties owing to their crystal structure. ${ }^{10)}$ The strength of ferritic steel significantly increases with decreasing temperature, while the elongation drastically decreases at a critical temperature and brittle fracture occurs. There are 48 slip systems, such as $\{110\}<1-11>,\{112\}<11-1>$, and 
$\{123\}<11-1>$, in ferritic steels. Above room temperature, the critical resolved shear stress is equal among these slip systems, and various slip systems can operate. However, at low temperatures, the critical resolved shear stress of the $\{110\}<1-11>$ slip system is lower than that of the other slip systems. ${ }^{11)}$ Thus, the 48 slip systems are restricted to only 12 slip systems at low temperatures. Furthermore, deformation twinning occurs at low temperatures in ferritic steel. ${ }^{12)}$ At room temperature, the stacking fault energy in ferritic steels is relatively high and deformation twinning does not occur. However, at low temperatures, deformation twinning occurs and causes brittle fracture through cleavage cracking at the grain boundaries induced by twins. ${ }^{13)}$ On the other hand, some alloying elements in ferritic steels, such as $\mathrm{Ni}$ and $\mathrm{Mn}$, provide solid solution softening at low temperatures in ferritic steels, even though they enhance strength at room temperature. ${ }^{14)}$ The mechanical properties, deformation behavior, and effect of solid solute alloying elements on the strength of ferritic steels at low temperatures are significantly different from those at room temperature.

In this study, the microstructural changes and lowtemperature tensile properties of ultra-low carbon steel with aging treatment were examined and the relationship between the low-temperature tensile properties and the ultra-low carbon state were discussed.

\section{Experimental Procedure}

\subsection{Material}

This study used an ultra-low carbon steel with a carbon concentration of 75 mass ppm. Table 1 presents the chemical composition of the steel. The steel was cold rolled to a $90 \%$ reduction in thickness, annealed at $973 \mathrm{~K}$ for $1.8 \mathrm{ks}$, and then water-cooled. The annealed specimens exhibited equiaxial recrystallized grains with an average grain size of approximately $50 \mu \mathrm{m}$. The annealed specimens were aged at $443 \mathrm{~K}$ for $0.06-600 \mathrm{ks}$ and subsequently water-cooled. The aged specimens were maintained at $77 \mathrm{~K}$ in liquid nitrogen to prevent further aging at room temperature.

\subsection{Tensile Tests}

Tensile test specimens with a gage length of $20 \mathrm{~mm}$, width of $4 \mathrm{~mm}$, and thickness of $2 \mathrm{~mm}$ were cut from plates where the tensile direction was parallel to the rolling direction (RD). Tensile testing was conducted at an approximate initial strain rate of $5.2 \times 10^{-4} \mathrm{~s}^{-1}$ at $293 \mathrm{~K}$ in air and at $77 \mathrm{~K}$ in liquid nitrogen. The tensile tests were initiated after the specimens were maintained at the test temperature for $1.8 \mathrm{ks}$.

\subsection{Microstructural Analysis}

The microstructure on the surface of the normal direction (ND) specimen was observed using field-emission scanning electron microscopy (FE-SEM). The specimen was polished

Table 1. Chemical composition of the ultra-low carbon steel (mass\%).

\begin{tabular}{cccccccc}
\hline $\mathrm{C}$ & $\mathrm{Si}$ & $\mathrm{Mn}$ & $\mathrm{P}$ & $\mathrm{S}$ & $\mathrm{Al}$ & $\mathrm{N}$ & $\mathrm{Fe}$ \\
\hline 0.0075 & $<0.003$ & $<0.003$ & $<0.002$ & $<0.0003$ & 0.006 & 0.0006 & bal. \\
\hline
\end{tabular}

with colloidal silica and etched with 3\% nital. Electron back-scattered diffraction (EBSD) with FE-SEM was used to analyze the crystal orientation in the ferrite matrix and twins. Data were recorded with the beam scanning step of $0.05 \mu \mathrm{m}$. Only data points with a confidence index exceeding 0.1 were used for the crystal orientation analysis using $\mathrm{OIM}^{\mathrm{TM}}$ software (version 7.0.1). A twin-jet electro-polisher, using methanol-perchloric acid with a volume ratio of methanol, 1-butanol, and perchloric acid of 12:7:1 at $233 \mathrm{~K}$, was employed to prepare the specimens for transmission electron microscopy (TEM) observations.

\subsection{Electrical Resistivity Measurements}

The electrical resistivity was measured by direct-current four-terminal sensing. The test specimen was cut longitudinally parallel to the RD to obtain samples of $22 \mathrm{~mm}$ in length, $10 \mathrm{~mm}$ in width, and $2 \mathrm{~mm}$ in thickness. The voltage at $77 \mathrm{~K}$ was measured while varying the current between 100 and $500 \mathrm{~mA}$, and the electrical resistance was calculated. The electrical resistivity was then calculated from the electrical resistance based on the specimen shape.

\subsection{Internal Friction Measurements}

Internal friction measurements on $60 \mathrm{~mm} \times 10 \mathrm{~mm} \times$ $1.0 \mathrm{~mm}$ samples were conducted to estimate the solute carbon concentration. The internal friction was measured every $5 \mathrm{~K}$ from 293 to $473 \mathrm{~K}$ with the resonant frequency of $170 \mathrm{~Hz}$ using an internal friction measurement device with free vibration (JE-HT, Nihon Techno-Plus Corp.). The measurement time at each temperature was approximately $60 \mathrm{~s}$, and the total measurement time was approximately $1.8 \mathrm{ks}$. The temperature corresponding to the peak internal friction was approximately $373 \mathrm{~K}$.

\subsection{Digital Image Correlation Method}

Digital image correlation analysis was performed on the SEM images before and after deformation with a subset of 41 pixels and a step of 3 pixels. VIC-2D software (Correlated Solutions Inc.) was used for the analysis.

\section{Results}

\subsection{Microstructure of Aged Ultra-low Carbon Steel}

Figures 1(a) and 1(b) show the maximum internal friction and electrical resistivity as a function of aging time at $443 \mathrm{~K}$, respectively. The changes in the maximum internal friction and electrical resistivity against aging time were identical, where both values decreased until $60 \mathrm{ks}$ and then stabilized. The maximum internal friction value strongly correlated with the solute carbon concentration in the ferrite matrix. ${ }^{15,16)}$ Electrical resistivity is influenced by many factors, such as the dislocation density, ${ }^{17)}$ amount of precipitates, ${ }^{18)}$ and grain size. ${ }^{19)}$ However, the main factor influencing the electrical resistivity in this analysis is the solid solute carbon concentration because the aging temperature was significantly lower than the temperature at which grain growth or recovery of dislocations occurs. Therefore, as shown in Fig. 1, the solid solute carbon in the ferrite matrix continuously decreased; specifically, the precipitate continuously increased until $60 \mathrm{ks}$ and then stabilized.

Figures 2(a)-2(f) display TEM images of the specimens 
aged at $443 \mathrm{~K}$ for $0,0.06,0.6,6,60$, and $600 \mathrm{ks}$, respectively. Precipitates were not observed at 0 and 0.06 ks (Figs. 2(a) and 2(b)). Considering that the solid solute carbon concentration decreased at $0.06 \mathrm{ks}$, as shown in Fig. 1, fine precipitates and clusters could be present or segregation of carbon atoms to dislocations and/or grain boundaries could have occurred. Meanwhile, precipitates of approximately $60 \mathrm{~nm}$ in length were observed at $0.6 \mathrm{ks}$ (Fig. 2(c)). These precipitates grew with increasing aging time (Figs. 2(d)2(e)) and were approximately $800 \mathrm{~nm}$ in length at $600 \mathrm{ks}$. The precipitate thickness was approximately $25 \mathrm{~nm}$, even

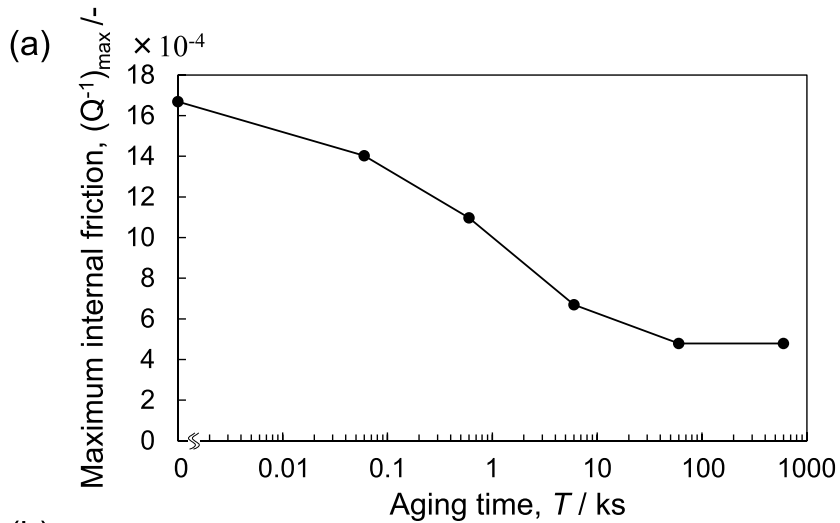

(b)

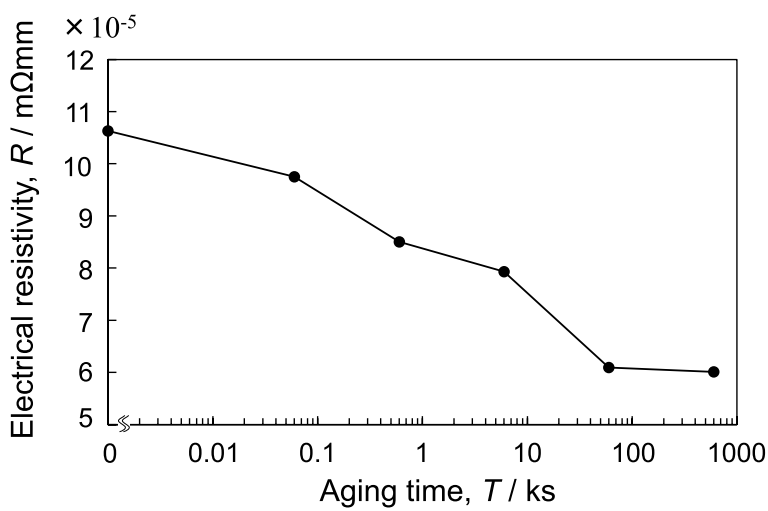

Fig. 1. (a) Maximum internal friction and (b) electrical resistivity as functions of the aging time at $443 \mathrm{~K}$. at $600 \mathrm{ks}$. As the solid solute carbon concentration continuously decreased until $60 \mathrm{ks}$, the nucleation and growth of precipitates was assumed to have occurred until $60 \mathrm{ks}$, after which Ostwald ripening occurred. Figure 3 shows an enlarged TEM image of the precipitates in the specimen aged at $443 \mathrm{~K}$ for $600 \mathrm{ks}$. The precipitates exhibited a plate-like shape, indicating that the specific precipitation/ ferrite interfacial boundaries preferentially grew. The angle between the precipitates was approximately $70^{\circ}$. The plane of the ferrite matrix at the ferrite/precipitate interfacial boundary was $\{110\} \alpha$. These results are consistent with the characteristics of cementites. ${ }^{20)}$ Furthermore, cementites have been observed in similar alloys under identical aging conditions. ${ }^{4)}$ Therefore, these were considered to be cementite.

\subsection{Tensile Properties at $293 \mathrm{~K}$ and $77 \mathrm{~K}$ in Aged Ultra-low Carbon Steel}

Figures 4(a) and 4(b) present the nominal stress-nominal strain (SS) curves at $293 \mathrm{~K}$ and $77 \mathrm{~K}$, respectively, for the specimens at various aging times. At $293 \mathrm{~K}$, the upper yield stress increased continuously until $60 \mathrm{ks}$ and it at

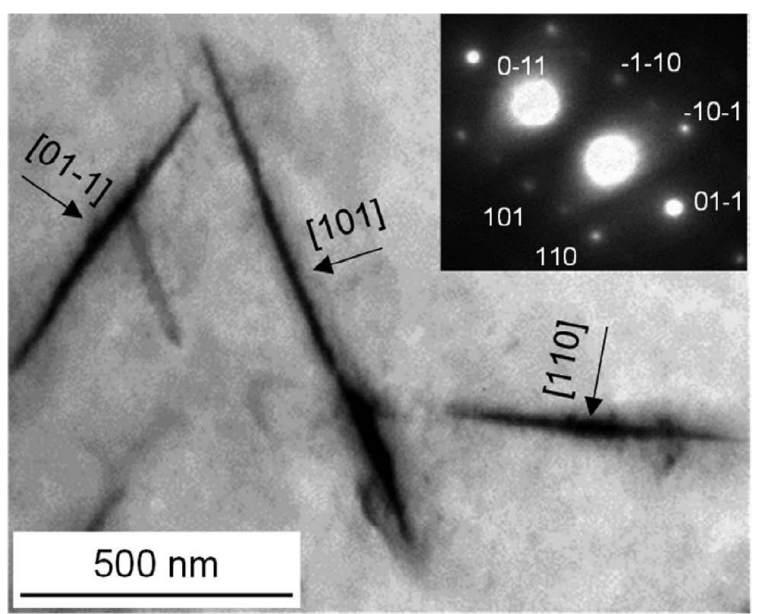

Fig. 3. Enlarged TEM image of the precipitates in the specimen aged at $443 \mathrm{~K}$ for $600 \mathrm{ks}$.
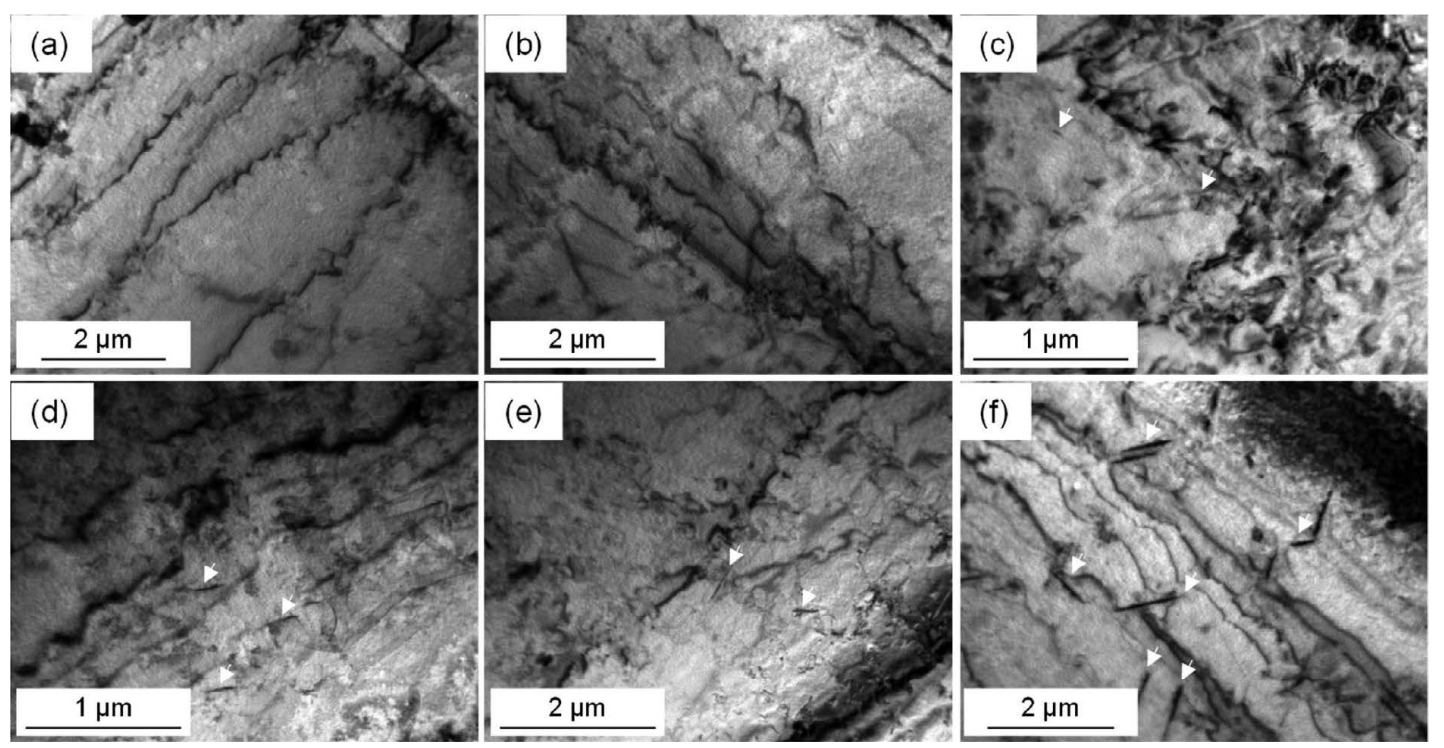

Fig. 2. TEM images of the specimens aged at $443 \mathrm{~K}$ for (a) $0 \mathrm{ks}$, (b) $0.06 \mathrm{ks}$, (c) $0.6 \mathrm{ks}$, (d) $6 \mathrm{ks}$, (e) $60 \mathrm{ks}$, and (f) $600 \mathrm{ks}$. 

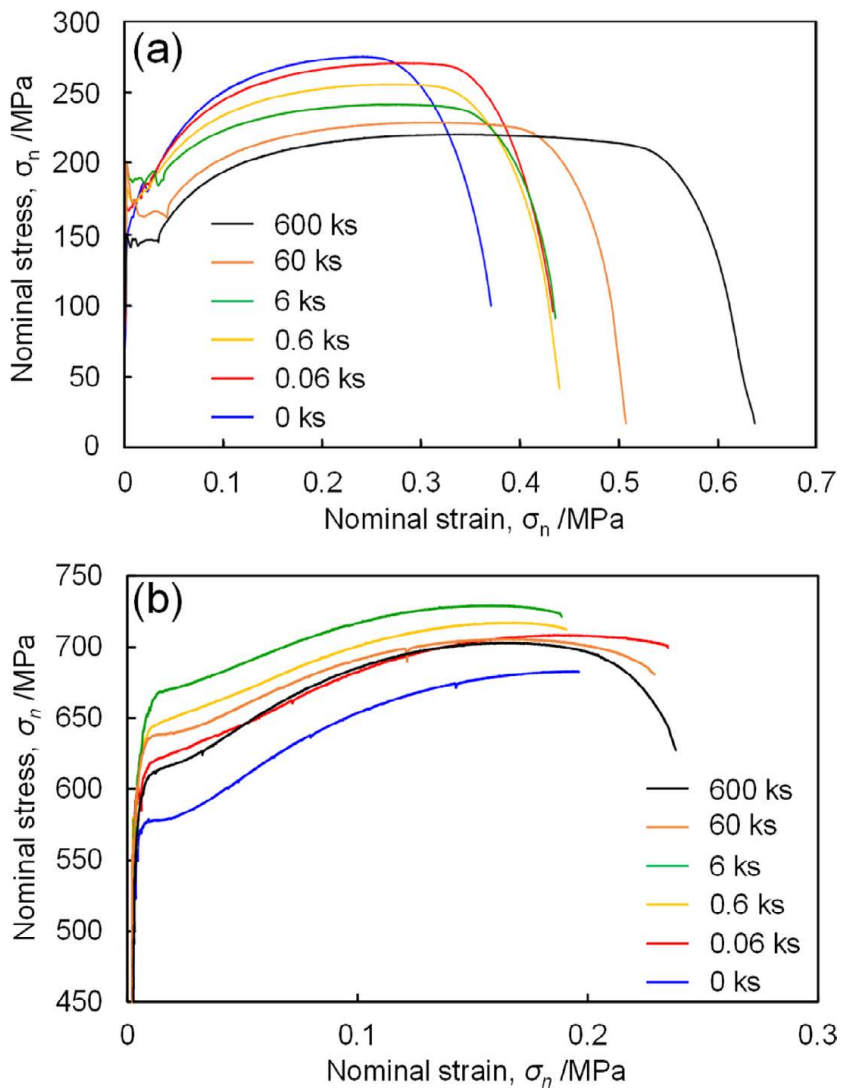

Fig. 4. Nominal stress-nominal strain curves of the specimens aged at various times tested at (a) $293 \mathrm{~K}$ and (b) $77 \mathrm{~K}$. (Online version in color.)

$600 \mathrm{ks}$ decreased to the stress level of the unaged specimen. Although some mechanisms for the increase in the upper yield stress have been proposed, ${ }^{21-23)}$ the segregation of carbon to dislocations, that is, the Cottrell atmosphere, during aging is the main contributor to the increase. In contrast, the tensile strength continuously decreased with increasing aging time. The strengthening by cementites may be lower than the solid solute strengthening by carbon, and the continuous decrease in solid solute carbon concentration with an increasing aging time may result in continuous decrease in tensile strength. On the other hand, Nakanishi et al. ${ }^{24)}$ demonstrated that the dislocation density after cold rolling increased with increasing solid solute carbon concentrations. Therefore, the decrease in solid solute carbon concentration due to aging may lead to a decrease in the increase of the dislocation density during tensile deformation, causing the lower tensile strength with an increasing aging time. The SS curves at $77 \mathrm{~K}$ and for all aging times exhibited low elastic limits, and the plateau regime appeared from an approximate nominal strain of 0.002 , following which work hardening occurred. A similar yielding behavior was observed in duplex-grained ferritic steel, and "micro-yielding" occurred preferentially in the coarse grains, ${ }^{25}$ ) which may be the reason for the characteristic yielding behavior of the duplex-grained steel. Herein, we refer to the three deformation stages as the "micro-yield", "macro-yield", and "work hardening" stages. The yield and tensile stresses increased until $6 \mathrm{ks}$ and then decreased; however, the specimen aged for $600 \mathrm{ks}$ exhibited higher strength than the unaged specimen. The total elongation did not significantly change as compared to that at $293 \mathrm{~K}$, indicating that the aging treatment improved the strength-elongation balance of ultra-low carbon steel at cryogenic temperatures. Therefore, the effect of ultra-low carbon on the tensile properties significantly depended on the test temperature.

\subsection{Deformation Behavior at $77 \mathrm{~K}$ in Aged Ultra-low Carbon Steel}

Figure 5 shows (a) a schematic illustration of the SS curve with interruption conditions and SEM images of identical regions (b) before deformation and the (c) elastic limit, and the (d) micro-yield stage, (e) macro-yield stage, and (f) work hardening stage in the unaged specimen. The elastic limit is defined as the point where the stress and strain linear relationship gradient during elastic deformation changes. Up to the elastic limit, the microstructure did not change (Figs. 5(b) and 5(c)). At the micro-yield stage (Fig. $5(d)$ ), bands appeared continuously across several grains, as indicated by the white arrows. Figure 6(a) shows an inverse pole figure around a band. Another crystallographic orientation grain from that of the matrix was detected inside bands, as indicated by the arrows. Additionally, the pole figure in Fig. 6(b) reveals that the band was a $\{112\}<11-1>$ deformation twin, which is generally observed in bcc metals. ${ }^{26)}$ Crystallographic orientation analyses were conducted on all bands in Fig. 5, and these were deformation twins. At the macro-yield stage (Fig. 5(e)), the number of deformation twins drastically increased and several twins were not continuous across grain boundaries, but independently occurred inside single grains. At the work hardening stage (Fig. 5(f)), the number of twins did not increase. Figure 7 shows the $\varepsilon_{\mathrm{xx}}$ strain distribution of the $6 \mathrm{ks}$ aged specimen subjected to 0.02 plastic strain. The colors in Fig. 7 denote the strain, and twins were observed, as indicated by black arrows. The high strain regions corresponded with these twinned regions, while the other regions were hardly deformed, indicating that deformation twinning generated high strain. It has been theoretically calculated that twinning generates high strain, ${ }^{27)}$ therefore, the generation of twins is closely related to micro- and macro-yielding.

Figure 8 shows (a) a low magnification SEM image of Fig. 5(d); (b) a schematic illustration of the relationship between the tensile direction, twin plane, and shear direction; and (c) the $\varepsilon_{\mathrm{xx}}$ strain distribution in the specimen subjected to testing to the elastic limit (Fig. 5(c)). Two twin nucleation sites were observed at the triple junction points of the grain boundaries, as indicated by the white and black dotted circles. Twins were continuously generated across the grain boundary, as indicated by the white arrows in Fig. 8(a). The resolved shear stress $\left(\tau_{\mathrm{RSS}}\right)$ to the shear direction on the twin plane was calculated using the following equation.

$$
\tau_{\mathrm{RSS}}=\sigma \cos \varphi \cos \theta,
$$

where $\varphi$ and $\theta$ are the angles between the tensile direction and the ND of the twin plane and the shear direction, respectively, and $\sigma$ is the applied stress, as shown in Fig. 8(b). $\tau_{\text {RSS }}$ is dominated by $\cos \varphi \cos \theta$; therefore, the difficulty of deformation twinning depends on $\cos \varphi \cos \theta$, similar to the Schmid factor of slip systems. The expression of $\cos \varphi \cos \theta$ is called the "Schmid factor for deformation twinning $\left(S F_{\text {twin }}\right)$." The 

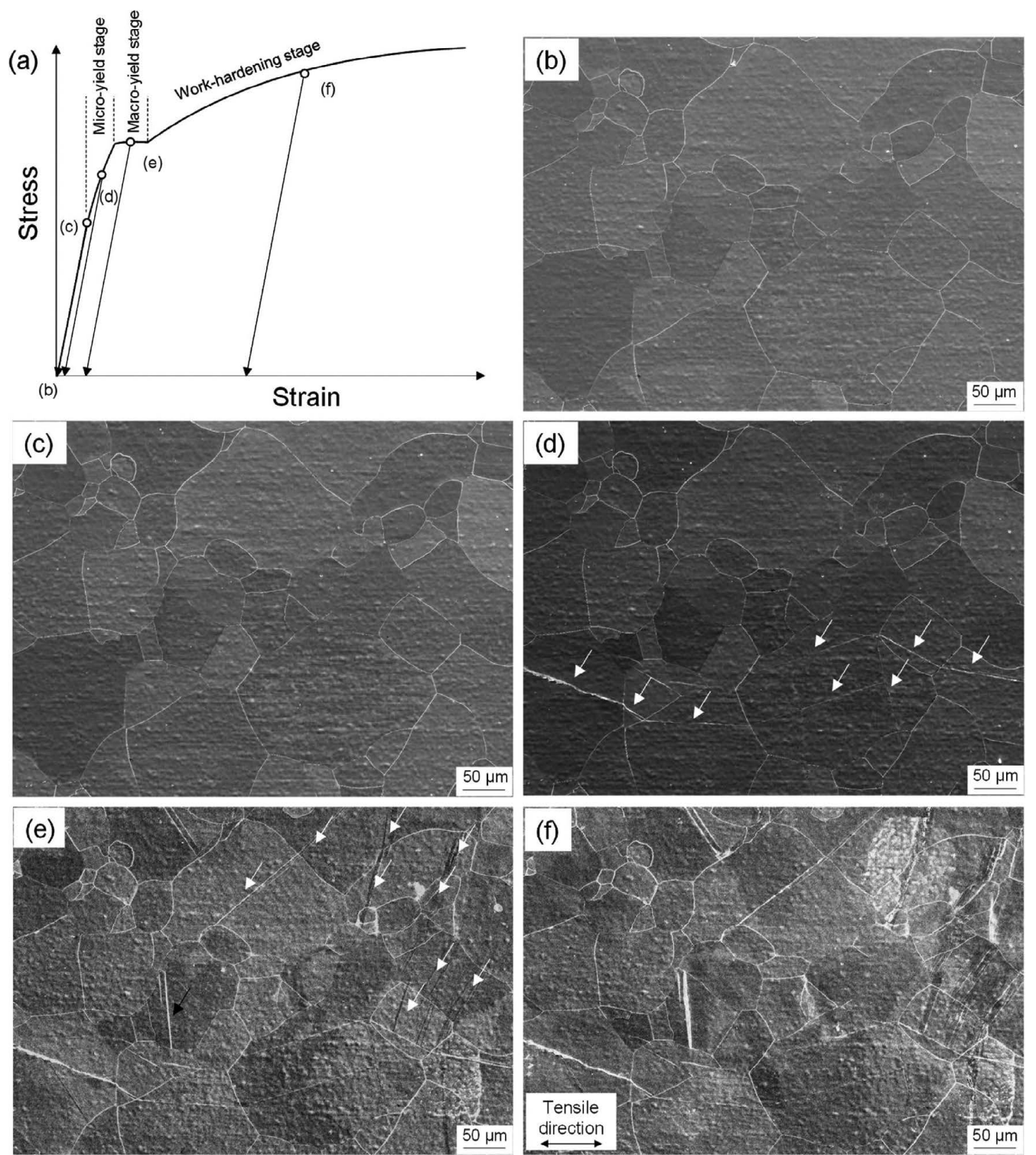

Fig. 5. (a) Schematic illustration of a stress-strain curve with interruption conditions, and SEM images of an identical region (b) before deformation, at the (c) elastic limit, (d) micro-yield stage, (e) macro-yield stage, and (f) work hardening stage in the unaged specimen.

activated twin system was determined from the SEM image and crystallographic data measured by EBSD, and then the $S F_{\text {twin }}$ of the twin system was calculated from the crystal orientation along the tensile direction. These resultant $S F_{\text {twin }}$ are shown in Fig. 8(a), and were relatively small (below 0.4 ), indicating that the macroscopic applied stress hardly induced these twins. The $\varepsilon_{\mathrm{xx}}$ strain distribution in the specimen subjected to the elastic limit (Fig. 8(c)) demonstrated that the twin nucleation site corresponded to the high-strain region at the triple junction point. Furthermore, it has been reported that the triple junction points of grain boundaries tend to be high-strain regions. ${ }^{28)}$ Therefore, it can be assumed that the stress concentration at the grain boundary led to the nucleation of the twin, and then the generated twin induced a twin in the neighboring grain, resulting in continuous twins across the grain boundary.

Figure 9 shows the length of the twin boundaries per unit area at the micro-yield, macro-yield, and work hardening stages in the unaged, 6 and $600 \mathrm{ks}$ aged specimens. The observation area was $1 \mathrm{~mm} \times 1 \mathrm{~mm}$. The deformation twins occurred until the micro-yield stage independent of the aging conditions. At the macro-yield stage, deformation twins increased in the unaged and $6 \mathrm{ks}$ aged specimens, but it negligibly increased in the $600 \mathrm{ks}$ aged specimen. The length of the twin boundaries per unit area at the work hardening stage was equal to those at the macro-yield stage in all the specimens. These results suggest a deformation process in which micro-yielding occurred in all the specimens by deformation twinning induced by local stress concentration at the grain boundary. In the unaged and 6 ks aged specimens, macro-yielding occurred as a result of deformation twinning, and then changed to slip deformation at the work hardening stage. However, in the $600 \mathrm{ks}$ aged specimen, macro-yielding occurred due to slip deformation because the length of the twin boundaries per unit area were constant independent of the deformation stage. The plateau regime within the macro-yield stage was due to the drastic increase in twins in the unaged and $6 \mathrm{ks}$ aged specimens. The $600 \mathrm{ks}$ aged specimen also exhibited a plateau regime, although the number of twins negligibly increased during the macro-yield 

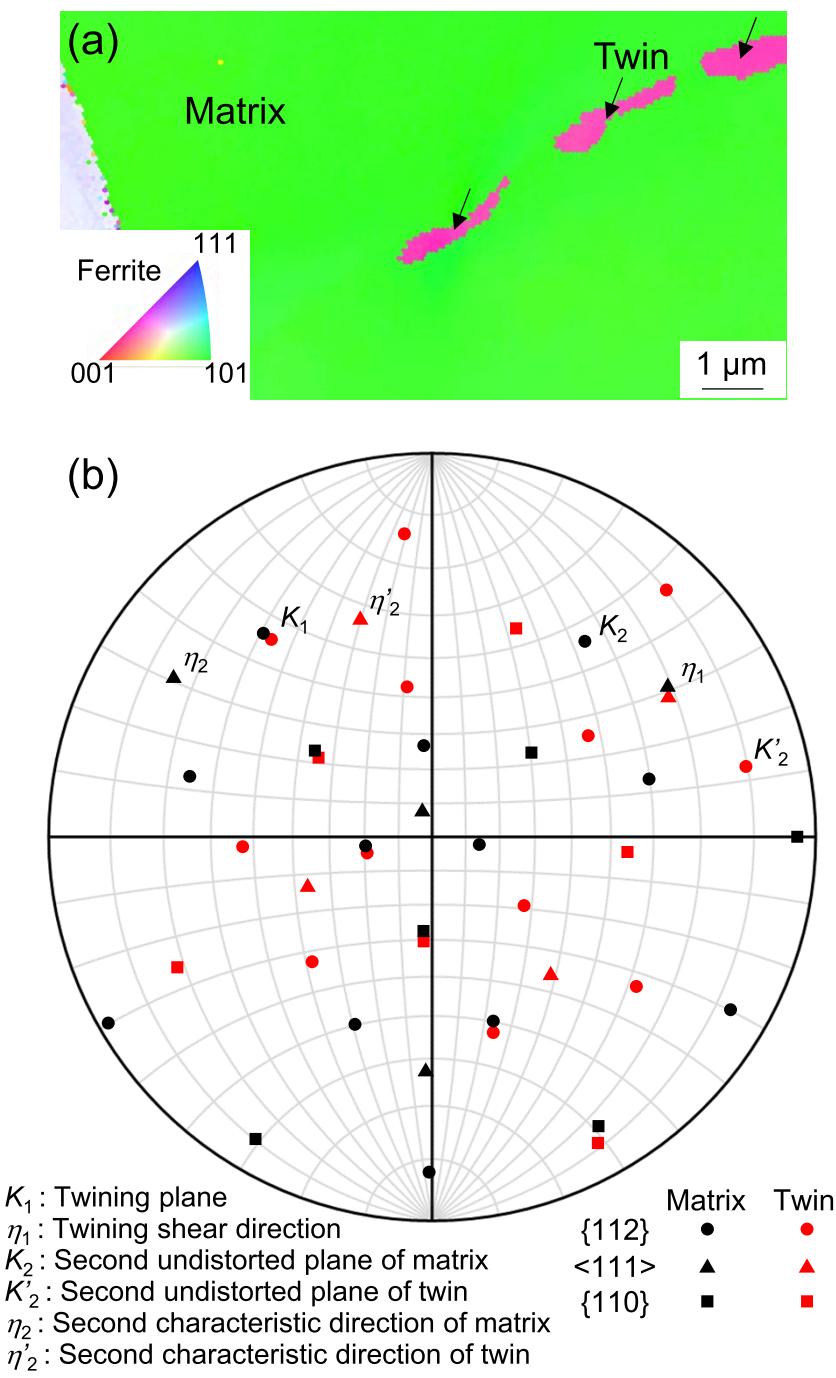

Fig. 6. (a) Inverse pole figure of ferrite phase and (b) pole figure of matrix and twin. (Online version in color.)

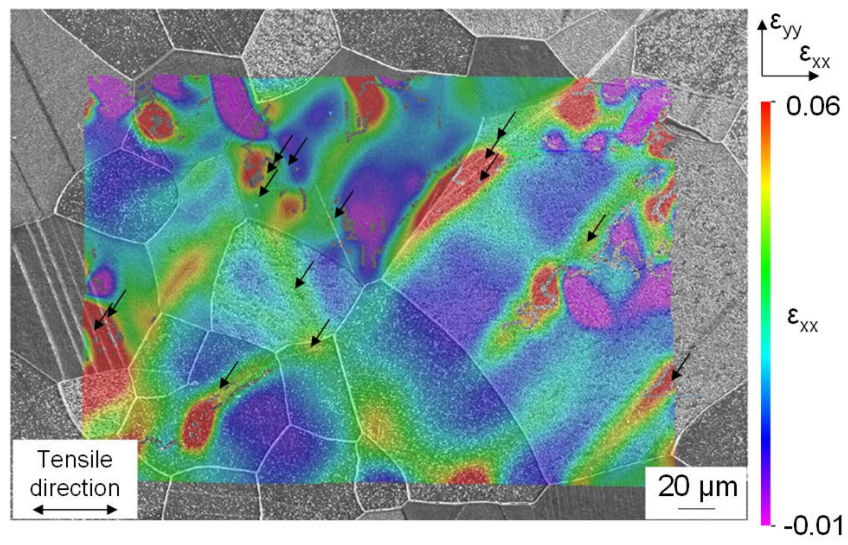

Fig. 7. $\varepsilon_{\mathrm{xx}}$ strain distribution of the $6 \mathrm{ks}$ aged specimen subjected to 0.02 plastic strain. (Online version in color.)

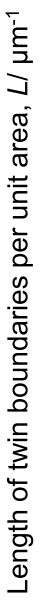

Fig. 9. Length of twin boundaries per unit area at the micro-yield, macro-yield, and work hardening stages in the unaged, 6 ks and $600 \mathrm{ks}$ aged specimens.

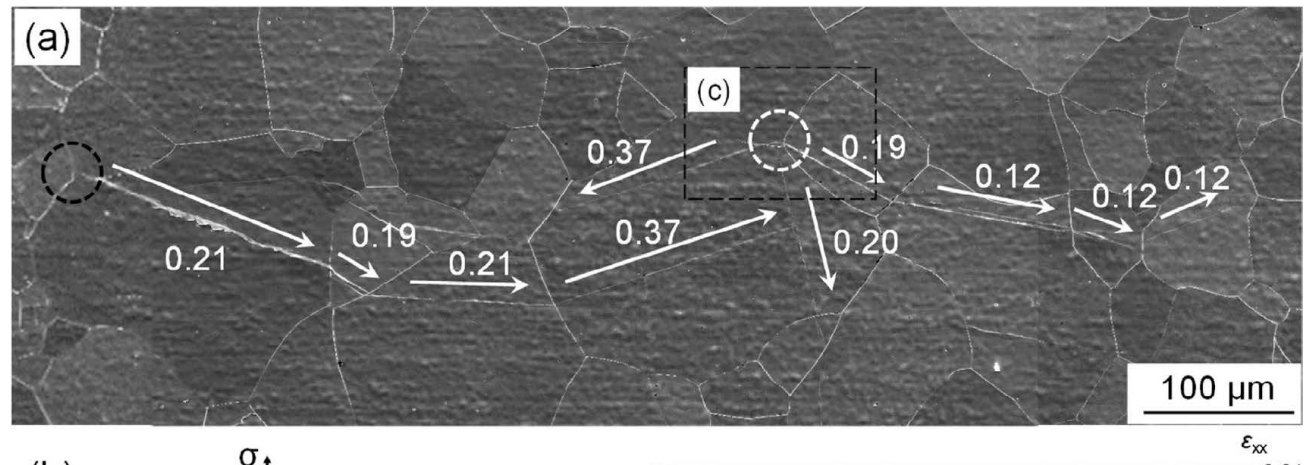

(b)

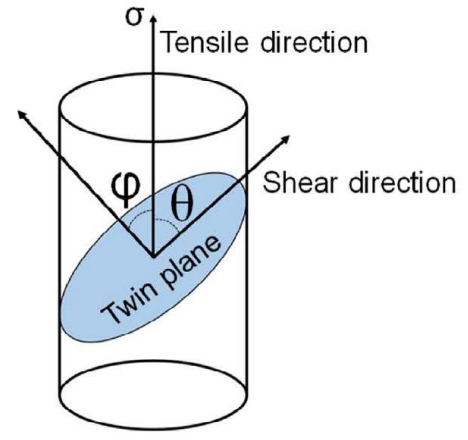

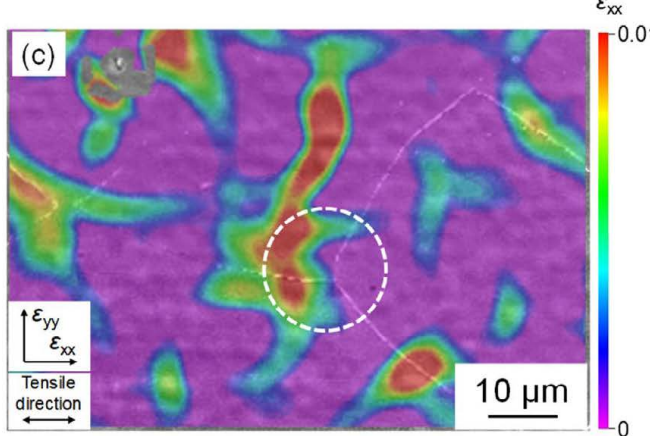

Fig. 8. (a) Low magnification SEM image of Fig. 5(d); and (b) schematic illustration of the relationship between the tensile direction, twin plane, and shear direction; and (c) the $\varepsilon_{\mathrm{xx}}$ strain distribution in the specimen subjected to testing to the elastic limit (Fig. 5(c)). (Online version in color.) 
stage. It is possible that the drastic increase in dislocations at the macro-yield stage resulted in the plateau regime, according to the Johnston-Gilman model, ${ }^{29,30)}$ however, details of this were unclear in this study. Thus, the change in the dislocation density during deformation must be measured to clarify the mechanism.

\section{Discussion}

Table 2 summarizes the macro-yielding stress at $77 \mathrm{~K}$, the solid solute carbon concentration, volume fraction of cementite, length of cementite, thickness of cementite, increase in strength by precipitation strengthening, and deformation mechanism during macro-yielding in the unaged, 6 and $600 \mathrm{ks}$ aged specimens. The solid solute carbon concentration was estimated from the maximum internal friction according to the following equation proposed by Sekino et al.: ${ }^{31)}$

$$
C(\mathrm{ppm})=k Q^{-1} \times 10^{-4},
$$

where $C$ is the solid solute carbon concentration; $k$ is a constant ranging from 1.5 to 1.8 , and $k=1.65$ was adopted in this calculation, and $Q^{-1}$ represents the maximum internal friction. Here, the solid solute carbon concentration of the unaged specimen must be underestimated because the specimen was subjected to high temperatures during the internal friction measurement, that is, aging occurred. Therefore, the actual solid solute carbon concentration should be greater than $27 \mathrm{ppm}$ in the unaged specimen. However, the aging time was longer than the measurement time $(1.8 \mathrm{ks})$ for the 6 and $600 \mathrm{ks}$ aged specimens; hence, the estimated solid solute carbon concentration should have a certain accuracy. The volume fraction of cementite was calculated from the carbon concentration precipitated as cementite, i.e., subtracting the solid solute carbon concentration from $75 \mathrm{ppm}$, and from the densities of ferrite $\left(7.87 \mathrm{~g} \mathrm{~cm}^{-332)}\right)$ and cementite (7.68 $\mathrm{g} \mathrm{cm}^{-333)}$ ), under the assumption that the saturated solid solute carbon concentration was $0 \mathrm{ppm}$ at $443 \mathrm{~K}$. The increase in strength by precipitation strengthening was calculated using the following Ashby-Orowan equation ${ }^{34)}$

$$
\Delta \sigma=0.84\left(\frac{1.2 G b}{2 \pi L}\right) \ln \left(\frac{d}{2 b}\right)
$$

Where $G$ and $b$ are the shear modulus and Burgers vector, equal to $80 \mathrm{GPa}$ and $0.25 \mathrm{~nm}$ in ferritic steels, respectively; $d$ is the average cross-sectional diameter of the precipitate on the slip plane; and $L$ is the distance between the precipitates. In the case of plate-like precipitates, $L$ and $d$ can be calculated using the following equations: ${ }^{.35}$

$$
\begin{gathered}
L=\left\{\frac{2 f \sin \theta}{\pi r t}\right\}^{-1 / 2}, \\
d=\frac{\pi}{4} 2 r, \ldots \ldots .
\end{gathered}
$$

where $f$ is the volume fraction of the precipitate; $r$ and $t$ are the radius and thickness of the precipitate, respectively, and half the length of the cementite was adopted as $r$ in this study; and $\theta$ is the angle between the precipitate and slip plane, and was assumed to be $60^{\circ}$ assuming that the habit plane of ferrite is $\{110\}$, and a $\{110\}<1-11>$ slip system, which differs from the habit plane, are activated.

The unaged specimen exhibited the lowest strength at $77 \mathrm{~K}$, although it exhibited the highest tensile strength at 293 K. Macro-yielding in the unaged specimen occurred because of deformation twinning; therefore, at $77 \mathrm{~K}$, the critical resolved shear stress $\left(\tau_{\mathrm{c}}\right)$ of slip deformation is larger than that of deformation twinning at the macro-yield stage, as shown in Fig. 10(a). As summarized in Table 2, aging up to $6 \mathrm{ks}$ increased the macro-yielding stress and decreased the solid solute carbon concentration. Additionally, fine cementites formed, while the deformation mechanism was unchanged from that of the unaged specimen; specifically, deformation twinning occurred. This suggests that the $\tau_{\mathrm{c}}$ of both slip deformation and deformation twinning increased with aging until $6 \mathrm{ks}$, as shown in Fig. 10(b). Because precipitates inhibit the formation of twins, ${ }^{36)}$ it is possible that fine cementite enhanced the $\tau_{\mathrm{c}}$ of deformation twinning. Another possible reason for the increase in $\tau_{\mathrm{c}}$ of deformation twinning is that the decrease in solid solute carbon concentration with aging may increase the stacking fault energy. According to the Cottrell and Bilby model, ${ }^{37)}$ stacking fault energy plays an important role in the nucleation of twins of bcc metals. Therefore, if solid solute carbon decrease the stacking fault energy, the $\tau_{\mathrm{c}}$ value of deformation twinning will increase with increasing aging time. The relationship between the $\tau_{\mathrm{c}}$ of deformation twinning and the precipitates, and the effect of solid solute carbon on the stacking fault energy has not yet been discussed, and further experimental and computational investigations are necessary.

The $600 \mathrm{ks}$ aged specimen exhibited a lower macroyielding stress than the $6 \mathrm{ks}$ aged specimen, and the deformation mechanism during macro-yielding changed from deformation twinning to slip deformation (Table 2). Thus, the decrease in $\tau_{\mathrm{c}}$ of slip deformation is the reason for the decrease in the macro-yielding stress in the $600 \mathrm{ks}$ aged specimen, as shown in Fig. 10(c). The solid solute carbon

Table 2. Macro-yielding stress at $77 \mathrm{~K}$, the solid solute carbon concentration, volume fraction of cementite, length of cementite, thickness of cementite, increase in strength by precipitation strengthening, and deformation mechanism during macro-yielding in the unaged, 6 and $600 \mathrm{ks}$ aged specimens.

\begin{tabular}{ccccccc}
\hline & $\begin{array}{c}\text { Macro-yielding } \\
\text { stress at 77 K (MPa) }\end{array}$ & $\begin{array}{c}\text { Solid solute carbon } \\
\text { concentration }(\mathrm{ppm})\end{array}$ & $\begin{array}{c}\text { Volume fraction of } \\
\text { cementite }\left(\times 10^{-4}\right)\end{array}$ & $\begin{array}{c}\text { Length of } \\
\text { cementite } \\
(\mathrm{nm})\end{array}$ & $\begin{array}{c}\text { Thickness of } \\
\text { cementite } \\
(\mathrm{nm})\end{array}$ & $\begin{array}{c}\text { Increase of strength } \\
\text { by precipitation } \\
\text { strengthening }(\mathrm{MPa})\end{array}$ \\
\hline Unaged & 570 & $>27$ & - & - & - & $\begin{array}{c}\text { Deformation } \\
\text { mechanism during } \\
\text { macro-yielding }\end{array}$ \\
$6 \mathrm{ks}$ & 670 & 11 & 9.8 & $110 \pm 20$ & $10 \pm 3$ & $17 \pm 3 \mathrm{MPa}$ \\
$600 \mathrm{ks}$ & 610 & 8 & 10.2 & $800 \pm 200$ & $26 \pm 5$ & $5 \pm 1 \mathrm{MPa}$ \\
\hline
\end{tabular}




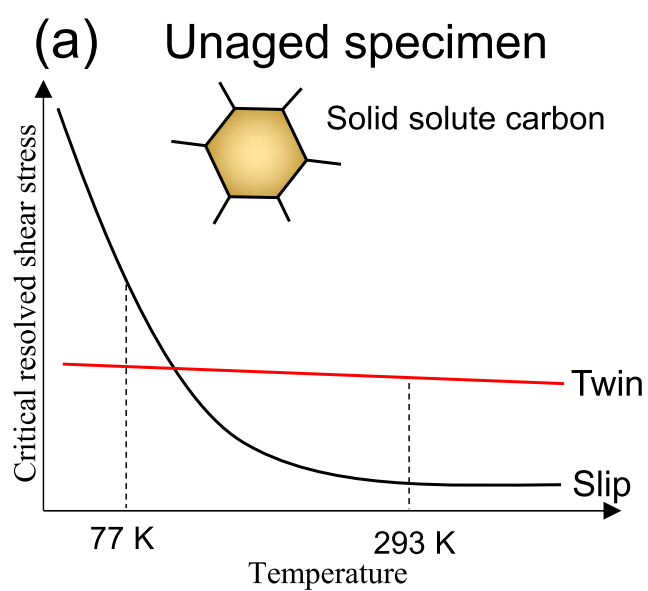

(b) $6 \mathrm{ks}$ aged specimen

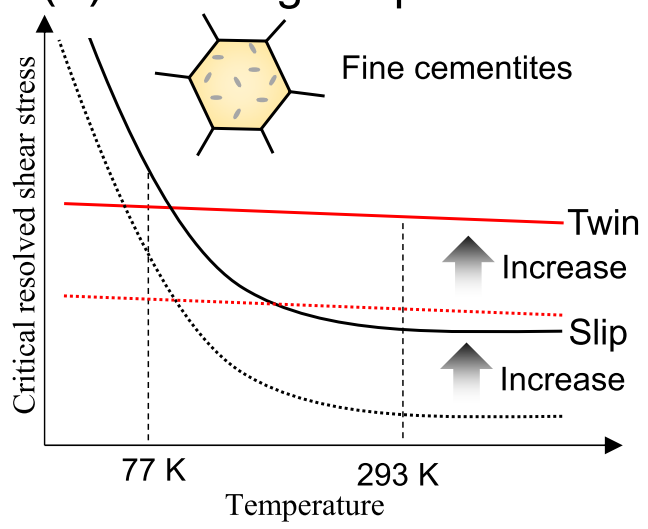

\section{(c) $600 \mathrm{ks}$ aged specimen}

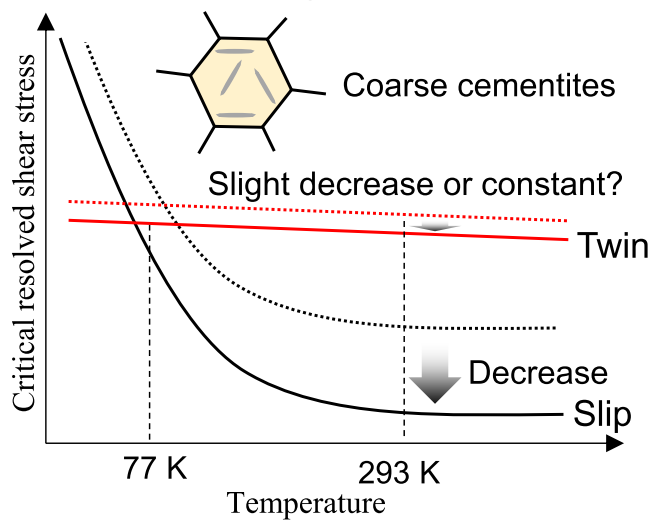

Fig. 10. Schematic illustration of the critical resolved shear stress for slip deformation and deformation twinning in the unaged, $6 \mathrm{ks}$ and $600 \mathrm{ks}$ aged specimens. (Online version in color.)

concentrations of the 6 and $600 \mathrm{ks}$ aged specimens were similar (Table 2), indicating that the increase in the size of cementite led to a decrease in $\tau_{\mathrm{c}}$ of slip deformation. The difference in the estimated strength increase by precipitation strengthening of cementites between the 6 and $600 \mathrm{ks}$ aged specimens was approximately $10 \mathrm{MPa}$, as shown in Table 2 , which is close to the difference in their macro-yielding stresses $(60 \mathrm{MPa})$. The difference in the shear modules between the matrix and precipitates, and the strain field derived from a misfit between the matrix and precipitates also influences the precipitation strengthening, ${ }^{38,39)}$ however, these factors were ignored in the present estimation, which may have caused the precipitate strengthening effect to be underestimated. The $600 \mathrm{ks}$ aged specimen exhibited higher macro-yielding stress than that of the unaged specimen, although the solid solute carbon concentration in the 600 ks aged specimen was considerably lower than that in the unaged specimen. This implies that the solid solute carbon negligibly strengthened or softened the steel at $77 \mathrm{~K}$. A similar temperature dependence of solid solute strengthening by carbon or nitrogen has been reported. ${ }^{40-42}$ )

In the unaged and $6 \mathrm{ks}$ aged specimens, deformation twinning changed to slip deformation at the work hardening stage. The $\tau_{\mathrm{c}}$ value of deformation twinning increased significantly with decreasing grain size. ${ }^{42)}$ The deformation twin divided the grains, and an increased number of deformation twins resulted in grain refinement. Deformation twins also enhance the critical stress of slip deformation because the twin boundary interrupts dislocation gliding. Sakui et al. ${ }^{43)}$ demonstrated that the dependence of the grain size on the yield stress by deformation twinning was larger than that by slip deformation. Therefore, grain refinement by deformation twins increased the $\tau_{\mathrm{c}}$ of deformation twinning more than that of slip deformation, causing a change in the deformation mechanism at the work hardening stage.

The addition of ultra-low carbon in ferritic steels strongly influences the mechanical properties not only above room temperature, but also at low temperatures. At low temperatures, the $\tau_{\mathrm{c}}$ values of both deformation twinning and slip deformation changed with aging treatment; therefore, the change in strength with aging treatment at $77 \mathrm{~K}$ differed from that at $293 \mathrm{~K}$.

\section{Conclusion}

The microstructural changes, and low-temperature tensile properties of ultra-low carbon steel with various aging treatments were examined and the relationship between the lowtemperature tensile properties and ultra-low carbon state was discussed. The main results are summarized as follows:

(1) The maximum internal friction and electrical resistivity decreased with increasing aging time at $443 \mathrm{~K}$, indicating that the solid solute carbon concentration decreased. Fine precipitates were observed at an aging time of $0.6 \mathrm{ks}$, and these grew to approximately $800 \mathrm{~nm}$ at $600 \mathrm{ks}$. It was concluded from the shape of the precipitates that these were cementite.

(2) At $293 \mathrm{~K}$, the tensile stress decreased continuously with aging. At $77 \mathrm{~K}$, both the yield and tensile stresses increased until the aging time of $6 \mathrm{ks}$, and then decreased until $600 \mathrm{ks}$. Under all aging conditions, the nominal stressnominal strain curves at $77 \mathrm{~K}$ exhibited low elastic limits, and the nominal stress plateau regime appeared at a nominal strain of approximately 0.002 , after which, work hardening occurred.

(3) In the unaged and $6 \mathrm{ks}$ aged specimens, several deformation twins occurred after the elastic limit and remarkably increased in the nominal stress plateau regime, indicating macroscopic yielding. At the work hardening stage, the number of deformation twins increased slightly. Therefore, macroscopic yielding occurred because of deformation twinning. In contrast, in the $600 \mathrm{ks}$ aged specimen, deformation twins negligibly increased at the macroscopic 
yield, indicating that macroscopic yielding occurred due to slip deformation.

(4) The $6 \mathrm{ks}$ aged specimen exhibited the highest strength, indicating that the critical resolved shear stress of deformation twinning increased as a result of fine cementites and/or a decrease in the solid solute carbon concentration. In the $600 \mathrm{ks}$ aged specimen, the cementite coarsened, which led to a decrease in the critical resolved shear stress of slip deformation. Hence, the deformation mechanism changed from twinning to slipping in the $600 \mathrm{ks}$ aged specimen and the strength decreased from that of the 6 ks aged specimen.

\section{Acknowledgement}

The authors acknowledge the financial support of the 28th ISIJ Research Promotion Grant, and the Grant-in-Aid for Scientific Research (KAKENHI) Grant No. 20K1460. The authors are also grateful to the KAMIJIMA NETSUSHORI Co., Ltd. for conducting the heat-treatment and Nihon Techno-Plus Corp. for conducting internal friction measurement.

\section{REFERENCES}

1) D. V. Wilson, B. Russell and J. D. Eshelby: Acta Metall., 7 (1959), 628.

2) D. V. Wilson and B. Russell: Acta Metall., 8 (1960), 36.

3) L. J. Baker, S. R. Daniel and J. D. Parker: Mater. Sci. Technol., 18 (2002), 355.

4) N. Maruyama and M. Takahashi: Tetsu-to-Hagané, 93 (2007), 506 (in Japanese)

5) K. Takeda, N. Nakada, T. Tsuchiyama and S. Takaki: ISIJ Int., 48 (2008), 1122.

6) S. Araki, K. Fujii, D. Akama, T. Tsuchiyama, S. Takaki, T. Ohmura and J. Takahashi: ISIJ Int., 58 (2018), 1920.

7) S. Araki, K. Mashima, T. Masumura, T. Tsuchiyama, S. Takaki and T. Ohmura: Scr. Mater., 169 (2019), 38.

8) M. Yamamoto, M. Watanabe, T. Yamamoto and K. Miyahara: J. Mater. Test. Res. Assoc. Jpn., 61 (2016), 86 (in Japanese).

9) N. Koga, O. Umezawa, M. Yamamoto, T. Yamamoto, T. Yamashita, S. Morooka, T. Kawasaki and S. Harjo: Metall. Mater. Trans. A, 52 (2021), 897.

10) R. P. Reed and A. F. Clark: Materials at Low Temperature, American
Society for Metals, Metals Park, OH, (1983), 256.

11) W. A. Spitzig and A. S. Keh: Acta Metall., 18 (1970), 1021.

12) D. Hull: Acta Metall., 8 (1960), 11.

13) A. Gilbert, G. T. Hahn, C. N. Reid and B. A. Wilcox: Acta Metall., 12 (1964), 754.

14) K. Okazaki: J. Mater. Sci, 31 (1996), 1087.

15) R. Hasiguti: Tetsu-to-Hagané, 60 (1974), 1706 (in Japanese).

16) S. Sekino and T. Fujishima: J. Jpn. Inst. Met., 39 (1975), 213 (in Japanese).

17) T. Kino: Bull. Jpn. Inst. Met., 12 (1973), 631 (in Japanese).

18) K. Osamura, N. Otsuka and Y. Murakami: Philos. Mag. B, 45 (1982), 583.

19) L. H. Qian, Q. H. Lu, W. J. Kong and K. Lu: Scr. Mater., 50 (2004), 1407.

20) W. C. Leslie, R. M. Fisher and N. Sen: Acta Metall., 7 (1959), 632.

21) A. H. Cottrell and B. A. Bilby: Proc. Phys. Soc. A, 62 (1949), 49.

22) A. H. Cottrell: Trans. Metall. Soc. AIME, 212 (1958), 192.

$23)$ T. Tsuchiyama, M. Araki and S. Takaki: Tetsu-to-Hagané, 106 (2020), 382 (in Japanese).

24) S. Nakanishi, T. Morikawa, K. Higashida, H. Murakami, K. Kimura and K. Ushioda: Tetsu-to-Hagané, 98 (2012), 253 (in Japanese).

25) R. Matoba, N. Nakada, Y. Futamura, T. Tsuchiyama and S. Takaki: Tetsu-to-Hagané, 93 (2007), 513 (in Japanese).

26) R. W. Cahn: Adv. Phys., 3 (1954), 363.

27) N. Narita: Bull. Jpn. Inst. Met., 24 (1985), 984 (in Japanese).

28) R. Tabata, H. Tsuruzono, S. Sadamatsu and Y. Adachi: Netsu Shori (J. Jpn. Soc. Heat Treat.), 55 (2015), 368 (in Japanese).

29) W. G. Johnston and J. J. Gilman: J. Appl. Phys., 30 (1959), 129.

30) J. J. Gilman and W. G. Johnston: Dislocations and Mechanical Properties of Crystals, John Wiley and Sons, New York, (1957), 116.

31) S. Sekino and T. Fujishima: J. Jpn. Inst. Met., 39 (1975), 213 (in Japanese).

32) S. Watanabe, Y. Tsu, K. Takano and Y. Shiraishi: J. Jpn. Inst. Met., 45 (1981), 242 (in Japanese).

33) M. Umemoto and K. Tsuchiya: Tetsu-to-Hagané, 88 (2002), 117 (in Japanese).

34) T. Gladman: The Physical Metallurgy of Microalloyed Steels, The Institute of Materials, London, (1997), 43.

35) K. Kutsumi, T. Senuma, M. Sugiyama, M. Suehiro and M. Nozaki: Shinnittetsu Giho, 381 (2004), 70 (in Japanese).

36) R. Hamano and K. Tsuya: Tetsu-to-Hagané, 58 (1972), 1415 (in Japanese).

37) A. H. Cottrell and B. A. Bilby: Philos. Mag., 42 (1951), 573.

38) K. C. Russell and L. M. Brown: Acta Metall., 20 (1972), 969.

39) V. Gerold and H. Haberkorn: Phys. Status Solidi B, 16 (1966), 675.

40) Y. Nakada and A. S. Keh: Acta Metall., 16 (1968), 903.

41) Y. Aono, K. Kitajima and E. Kuramoto: Scr. Metall., 14 (1980), 321

$42)$ D. J. Quesnel, A. Sato and M. Meshii: Mater. Sci. Eng., 18 (1975), 199.

43) S. Sakui and T. Sakai: Tetsu-to-Hagané, 58 (1972), 1438 (in Japanese). 